\title{
Un estudio de la relación entre la memoria, la narrativa y el lenguaje en alumnado con trastorno específico del lenguaje (TEL)*
}

A Study of the Relationship between Memory, Narrative and Language in Pupils with Specific Language Impairment (SLI)

Recibido: julio 29 de 2013 | Revisado: julio 27 de 2014 | Aceptado: enero 05 de 2015

\author{
Víctor Acosta ** \\ Universidad de La Laguna, Islas Canarias \\ Gustavo M. RAMÍREZ \\ Universidad de La Laguna, Islas Canarias \\ SERGIO HERNÁNDEZ \\ Universidad de La Laguna, Islas Canarias
}

doi: 10.11144/Javeriana.upsy14-2.ermn

Para citar este artículo: Acosta, V., Ramírez, G., \& Hernández, S. (2015).Un estudio de la relación entre la memoria, la narrativa y el lenguaje en alumnado con trastorno específico del lenguaje (TEL). Universitas Psychologica, 14(2), 631-644. http://dx.doi. org.10.11144/Javeriana.upsy14-2.ermn

Este trabajo se ha desarrollado a través de la financiación del Ministerio de Economía y Competitividad del Gobierno de España. Proyecto de Investigación Funciones ejecutivas y lenguaje en alumnado con TEL. Un modelo de evaluación e intervención con bases psicolingüística y neuropsicológica. Referencia EDU2011-27789.

** Departamento de Didáctica e Investigación Educativa. C/ Delgado Barreto s/n. Edificio Central de la Universidad de La Laguna. 38204 La Laguna. Tenerife. Islas Canarias. Teléfono: 922316502 (ext. 9025), 922317868. Correo electrónico: vacosta@ ull.es

\section{RES UMEN}

En esta investigación se estudiaron las relaciones entre el lenguaje, la narrativa y la memoria en alumnado con Trastorno Específico del Lenguaje (TEL). La muestra estuvo compuesta por 32 alumnos con TEL y 23 niños con desarrollo típico, diagnosticados con el CELF-3, el Peabody, el ITPA, el Subtest de Dígitos del WISC-IV, el Subtest de Localización Espacial de la WMS-III y la tarea del recontado del cuento Rana, idónde estás?. Los resultados obtenidos relacionan estrechamente la memoria de trabajo y la superestructura narrativa. Además, se distinguen tres subtipos de TEL atendiendo al déficit en memoria. Finalmente, entre todas las dimensiones que conforman el diagnóstico del TEL, son los problemas narrativos los que permiten advertir de mayores dificultades en la memoria.

Palabras clave

lenguaje; memoria; narrativa; trastorno específico del lenguaje

\section{A B S T R A C T}

This research studied the links between language, narrative and memory in Specific Language Impairments (SLI) students. The sample consisted of 32 children diagnosed with SLI and 23 typically developed children, according to different tests as CELF-3, Peabody, ITPA, Digit Span subtest of the WISC-IV, Spatial Span subtest of the WMS-III and the task of retelling the tale Frog, where are you?. The results show a close connection between working memory and narrative superstructure. Besides, three SLI subtypes could be differentiated according to the memory deficits. Finally, among all dimensions that allow the diagnosis of SLI, the narrative problems aware us of bigger memory difficulties.

Keywords

language; memory; narrative; specific language impairment 


\section{Introducción}

Los niños con Trastorno Específico del Lenguaje (TEL) presentan dificultades importantes en su desarrollo lingüístico que se ponen de manifiesto en la mayoría de sus componentes, entre los que cabría señalar el fonológico, el morfosintáctico, el semántico, el pragmático y el discursivo, tanto oral como escrito. En niños hispanohablantes se han encontrado errores fonológicos expresados en las omisiones de sílabas y en la reducción de la estructura silábica (Aguilar, Sanz-Torrent, \& Serra, 2002). Además Bedore y Leonard (2001) señalan errores en los morfemas nominales, en los pronombres clíticos, en la concordancia del adjetivo y en las marcas verbales. Posteriormente, SanzTorrent (2002) y Sanz-Torrent, Serrat, Andreu y Serra (2008) reseñaron errores morfológicos como el uso inadecuado del plural, de las marcas de género y de la flexión verbal. Tradicionalmente su diagnóstico se ha efectuado mediante criterios de exclusión atendiendo a dificultades severas en uno o varios elementos del lenguaje en ausencia de déficits significativos en otros dominios cognitivos, motores y sensoriales (Acosta, Moreno, \& Axpe, 2012; Hincapié et al., 2008). A pesar de la pretendida especificidad del trastorno, existen estudios que señalan déficits no lingüísticos en TEL, en particular en memoria y en funciones ejecutivas (Verche, Hernández, Quintero, \& Acosta, 2013; Quintero, Hernández, Verche, Acosta, \& Hernández, 2013; Im-Bolter, Johnson, \& Pascual-Leone, 2006; Marton, Campanelli, Eichorn, Scheuer, \& Yoon, 2014), cuestión que podría explicar en parte el progreso limitado que tienen estos niños cuando se les expone a programas de intervención de naturaleza estrictamente lingüística.

La situación descrita enfatiza la importancia de investigar las causas o mecanismos subyacentes de naturaleza neuropsicológica que puedan ayudar al conocimiento del trastorno y contribuir a su mejor caracterización y pronóstico en relación con su intervención psicopedagógica y fonoaudiológica. En esta dirección son numerosos los trabajos que objetivan desórdenes en la población con TEL, en mecanismos cognitivos no lingüísticos tales como el procesamiento conceptual, la percepción auditiva, la velocidad o capacidad del procesamiento, las representaciones fonológicas en la memoria de trabajo, la memoria procedimental o el procesamiento temporal (Gabriel, Stefaniak, Maillart, Schmitz, \& Meulemans, 2012; Gillam, Cowan, \& Marler, 1998; Ullman \& Pierpont, 2005). Entre todos ellos es quizás el tema de la memoria de trabajo (MT) el que reviste una mayor importancia, por su estrecha relación con el aprendizaje en general y del lenguaje (oral y escrito) en particular (Cain, Oakhill \& Bryant, 2004). Por todo ello, en este artículo se estudian las relaciones entre la MT y diferentes aspectos del lenguaje en niños con TEL en edad escolar.

Podemos definir a la memoria como la capacidad de adquirir, retener y evocar información siendo posible distinguir, según su dimensión temporal, una memoria a corto plazo (MCP) y una memoria a largo plazo (MLP). La MCP puede ser conceptualizada como almacén provisional de la información derivada de los sentidos. Su capacidad en términos de unidades de información es limitada y tiene una duración que no excede unos pocos minutos. Para algunos autores, no sin discusión, la MCP es un término intercambiable con el de Memoria de Trabajo (MT) (Baddeley, 2012). Una diferenciación entre ambas formas de memoria la encontramos en el hecho de que mientras la MCP sería el mantenimiento de la información, en la MT la información experimenta procesos de control y manipulación (Baddeley, 2012). Por ello la MT resulta vital para el lenguaje, pues ayuda a que la información esté activa y/o disponible para, por ejemplo, poder procesar el vocabulario en el léxico mental o seguir las acciones y salvar los obstáculos que involucran a varios personajes en el curso de una narración. De esta última reflexión se desprende su importancia en la adquisición de la superestructura narrativa (la presentación con personajes, atributos, contextos y problema que genera u origina el relato; el episodio con la meta, la acción, el obstáculo y el resultado; y el final donde se resuelve el conflicto que generó la historia (Pavez, Coloma, \& Maggiolo, 2008), también denominada gramática de las historias. 
La revisión de la literatura pone de manifiesto un importante acuerdo sobre la existencia de déficits en memoria de trabajo (MT) en TEL (ContiRamsden, Botting, \& Faragher, 2001; Ellis Weismer, Tomblin, Zhang, Buckwalter, Chynoweth, \& Jones, 2000). Con todo, este consenso disminuye a la hora de considerar a la MT en función de la naturaleza del material a memorizar (verbal o espacial). Así, hay tres posiciones claramente definidas. En primer lugar, la que defiende la presencia de déficits en la MT espacial (Bavin, Wilson, Maruff, $\&$ Sleeman, 2005); en segundo lugar, la que objetiva déficits en la MT verbal como un marcador clínico de los TEL (Archibald \& Gathercole, 2006; Ghatercole \& Baddeley, 1990); y en último lugar, la que sostiene que los niños con TEL evidencian problemas en la MT tanto espacial como verbal, por lo que sugieren la presencia de restricciones en la memoria que exceden del déficit lingüístico per se (Verche, et al., 2013).

Una capacidad de almacenamiento más pobre, con dificultades en la codificación y sin emplear estrategias que favorezcan el recuerdo pone de manifiesto problemas cognitivos en el TEL más allá de los lingüísticos propios de este trastorno. No es de extrañar, por tanto, que las alteraciones de la memoria en el TEL subyazcan a un pobre aprendizaje del lenguaje, explicando de esta manera sus problemas en diferentes componentes lingüísticos, entre ellos los que afectan al discurso narrativo. Así, tal y como se mencionó anteriormente, se ha señalado la presencia de producción de historias mucho más limitadas en cuanto a la cantidad de información relevante y a su superestructura. Se establece la hipótesis de que estos déficits tienen una razón etiológica que los explica en las alteraciones en funciones ejecutivas en esta población, entre las que cabría destacar la MT (Verche et al., 2013). De igual forma, en trabajos recientes que abordan la posible relación entre la MT y la narrativa, Dodwell y Bavin (2008) encontraron una correlación significativa entre la MT y una tarea de recontado de una historia, con niños con TEL de seis años.

En el presente estudio, el primer objetivo consiste en analizar cómo se agrupan los instrumentos utilizados en la evaluación de los TEL, es decir, la superestructura narrativa y las dos modalidades de memoria espacial y verbal, en sus formas memoria de corto plazo (MCP) y memoria de trabajo (MT). En segundo lugar, obtener distintos subgrupos de niños con TEL en función del déficit en las dos modalidades de memoria, esto es, MCP y MT y en la superestructura narrativa. Tras la revisión de la literatura no hemos encontrado otro trabajo en el que se pretenda el establecimiento de subgrupos de TEL apelando conjuntamente a variables lingüísticas y neuropsicológicas. Para finalizar, como tercer objetivo, se pretende estudiar las relaciones existentes entre los déficits de memoria y los distintos componentes del lenguaje estudiados para el diagnóstico de los TEL.

\section{Método}

\section{Participantes}

En la presente investigación participaron un total de 32 alumnos diagnosticados con TEL y 23 niños con un desarrollo normativo del lenguaje, escolarizados en 19 colegios en la Isla de Tenerife. Para la selección de la muestra de niños con TEL se hizo un cribado inicial en toda la isla, en colaboración con los Equipos de Orientación Educativa y Psicopedagógica. Una vez explicados cuáles eran nuestros objetivos se les pedía la remisión de alumnado con características de TEL, es decir que tuvieran problemas en la comprensión y/o la expresión del lenguaje, en uno o en varios de sus componentes, especialmente en la morfosintaxis, o que finalmente, presentaran varios años con dificultades de lenguaje no resueltas. Una vez enviados los alumnos, se les administraba un protocolo exhaustivo de evaluación para confirmar el diagnóstico, constituido por diversas pruebas estandarizadas.

La selección de los niños con desarrollo típico (grupo control) se efectuó entre los compañeros de curso de los niños con TEL. Estos alumnos no tenían problemas de lenguaje y seguían una escolarización dentro de los parámetros habituales. Se comprobó la normalidad de la edad mediante la prueba de Kolgomorov-Smirnov $(z=0.85 ; p=$ 0.47). Para comprobar que los grupos estaban igua- 
lados en dicha variable, se realizó un contraste de hipótesis $(F(2.53)=1.57 ; p=0$.218). Como paso previo se determinó la homogeneidad de varianzas mediante la prueba de Levene $(F(2.53)=0.90 ; p$ $=0.414)$. Las características de ambos grupos se describen en la tabla 1 .

\section{Instrumentos para la selección} de los niños con TEL

Inicialmente se atendieron algunos criterios de exclusión relacionados con el TEL que están presentes en la literatura, como es el caso de que en la historia escolar de estos niños no apareciesen problemas importantes, especialmente en su audición y en su motricidad oro-facial. Posteriormente y debido a la escasez de pruebas en español se siguió la sugerencia de utilizar varias pruebas de lenguaje, con el propósito de confirmar los resultados en al menos dos de ellas. En primer lugar, se recurrió al test más usado internacionalmente para el estudio de este trastorno, el CELF-3 (Semel, Wiig, \& Secord, 2003) que en un estudio previo, a través de un análisis discriminante, demostró ser el instrumento que mejor identificaba y diferenciaba a los niños TEL de los que tenían desarrollo típico (Acosta, Ramírez, \& Hernández, 2013). Se trata de un test de evaluación del lenguaje con baremos para hablantes del español de los Estados Unidos de América. Evalúa los procesos de comprensión y expresión lingüísticas con carácter general, mediante tareas de estructuración y formulación de las oraciones, conceptos y direcciones, estructura y clases de palabras, y recordar oraciones. Los resultados en esta prueba fueron cruciales, obteniéndose puntuaciones medias por debajo de -1.25 DT, en su capacidad lingüística, tal y como exigen autores tan relevantes como Leonard (2014). Con todo y dado que algunos investigadores señalan la necesidad de utilizar dos o más medidas de lenguaje, se dispuso, por un lado, del Peabody (Dunn, Padilla, Lugo, \& Dunn, 1986). En esta prueba se mide el vocabulario y el niño deberá señalar entre cuatro imágenes aquélla que corresponda a la palabra emitida por el evaluador. El vocabulario empleado consta de nombre de objetos, situaciones, profesiones y animales, de acciones y de atributos. Y, por otro lado, de dos subpruebas del ITPA (Kirk, McCarthy, \& Kirk, 2005), las de Asociación Auditiva y Asociación Visual, para evaluar procesos psicolingüísticos semánticos, mediante la asociación de términos a una palabra dada y de imágenes que guardan una relación taxonómica o temática. En ambas subpruebas los niños obtuvieron, del mismo modo, unos resultados muy deficitarios, reflejados en las puntuaciones negativas en lo que se refiere al Peabody, y a una edad psicolingüística en el ITPA muy inferior a la edad cronológica. Finalmente, se comprobó que los niños con TEL tuvieran un CI No-Verbal, por encima de la puntuación 85, a través del Test de Inteligencia K-BIT (Kauffman \& Kauffman, 2000). Todos estos datos quedan recogidos en la tabla 2.

\section{Procedimiento para la evaluación narrativa}

Una vez diagnosticados los niños con TEL se procedió a una evaluación de sus habilidades narrativas. El material utilizado ha sido el cuento Rana, idónde estás? (Mayer, 1969) usado con mucha frecuencia en este tipo de estudios (Strömqvist \& Verhoeven, 2004). Este libro de ficción consta de una serie de láminas ilustradas y sin palabras, cuya trama invo-

TABLA 1. Características de los grupos

\begin{tabular}{lcccccc}
\hline \multirow{2}{*}{ Grupo } & \multicolumn{3}{c}{ Género } & \multicolumn{4}{c}{ Edad } \\
\cline { 2 - 7 } & Niños & Niñas & Mínimo & Máximo & Media & D.T. \\
\hline Grupo TEL & 26 & 6 & 6.08 & 11.25 & 7.99 & 1.39 \\
Grupo Control & 15 & 8 & 6.00 & 11.67 & 8.20 & 1.70 \\
\hline
\end{tabular}

Fuente: elaboración propia 
TABLA 2. Resultados de las pruebas para la evaluación diagnóstica del grupo TEL

\begin{tabular}{lcc}
\hline \multicolumn{1}{c}{ Pruebas } & \multicolumn{2}{c}{ Grupo TEL } \\
\cline { 2 - 3 } & Media & D.T. \\
\hline CELF-3. Lenguaje Expresivo. Desviación típica & -1.37 & 0.84 \\
CELF-3. Lenguaje Receptivo. Desviación típica & -1.27 & 0.64 \\
PEABODY. Desviación estándar & -1.51 & 1.22 \\
ITPA. A. Auditiva. Edad Psicolingüística & 3.79 & 2.36 \\
ITPA. A. Visual. Edad Psicolingüística & 5.24 & 2.39 \\
RFI. Número de palabras erróneas & 15.14 & 14.30 \\
RFI. Número de fonemas erróneos & 15.74 & 16.41 \\
K-BIT. CI No Verbal & 102.54 & 9.56 \\
\hline
\end{tabular}

Fuente: elaboración propia

lucra a un niño y a un perro en la búsqueda de su rana perdida y los personajes y las aventuras con las que se encuentran durante este proceso. Las 24 láminas presentan una secuencia de eventos, con un cierto predominio de acciones simultáneas e imágenes difusas. Esta complejidad visual obliga a establecer relaciones verbales, con especial atención a los personajes y a la secuencia de los acontecimientos. Para comenzar la tarea, la fonoaudióloga narra el cuento, ayudada por un guión que servía como relato mientras se presentaban las imágenes y además, garantizaba la misma historia a todos los niños. Luego se lo da al niño y le pide que lo cuente. Finalmente y una vez registrada en audio la producción narrativa de los niños, se procedió a su transcripción literal y a su estudio.

El examen posterior consistió por un lado, en contabilizar el número total de oraciones (simples y compuestas), de problemas en la fluidez (mazes) y de errores gramaticales, es decir, producciones con un único error (omisión, sustitución, o adición) léxico o bien con una inadecuada incorporación de los rasgos morfológicos en alguna de las palabras que conforman la oración, pero que no impiden extraer el significado que se expresa como por ejemplo errores de concordancia, sustituciones de preposiciones u omisiones de artículos. La segunda arista del examen consistió en un análisis de la superestructura narrativa distribuyéndose las puntuaciones entre 1 (inexistencia de estructura narrativa), 2 (presencia de la presentación y de un episodio incompleto), 3 (presencia de la presentación y de un episodio completo), 4 (presencia de la presentación y de dos episodios completos) y 5 (presencia de la presentación, los episodios y el final; por lo tanto aparición de todos los elementos superestructurales). Cuatro fonoaudiólogas con más de diez años de ejercicio profesional hicieron los primeros análisis. Posteriormente los autores de este artículo revisaron todo el proceso de segmentación, etiquetado de oraciones y cláusulas y asignación de los elementos de la historia, mediante un procedimiento de discusión y consenso.

\section{Procedimiento para la evaluación de la memoria}

Para la evaluación de la memoria verbal hemos utilizado el Subtest de Dígitos del WISC-IV (Wechsler, 2005) que mide memoria a corto plazo (MCP) en su versión de aplicación directa y memoria de trabajo verbal (MT) en su aplicación inversa. El niño debe repetir en el mismo orden, o en orden inverso una lista de números que le dice el evaluador de forma oral. La cantidad de dígitos que debe retener aumenta progresivamente y dispone de dos ensayos. Si falla en ambos se finaliza la aplicación. Se registra el span máximo de números que es capaz de repetir. Para la evaluación de la memoria espacial hemos utilizado el Subtest de Localización Espacial de la WMS-III (Wechsler, 1997) que mide memoria a corto plazo espacial (MCP) en su versión de aplicación directa y memoria de trabajo espacial (MT) en su aplicación inversa. En 
un tablero con nueve cubos el evaluador va tocando los mismos y el participante debe tocarlos en el mismo orden o en orden inverso. La cantidad de cubos que debe tocar aumenta progresivamente. Hay dos secuencias por cada nivel y si falla en las dos se finaliza la administración de la prueba. Se registra el span máximo que puede reproducir. El déficit en ambos tipos de memoria en población infantil viene determinado por una puntuación igual o inferior a un span de 3.

\section{Análisis de datos}

Todos los análisis estadísticos de la investigación se realizaron con el paquete estadístico SPSS para Mac (versión 22). Como análisis previo se comprobó si las pruebas permitían diferenciar estadísticamente entre los niños del grupo de control y los niños con TEL.

En primer lugar, se desarrolló un análisis discriminante para comprobar qué pruebas de evaluación nos ayudan a discriminar con mayor precisión entre ambos grupos.

Posteriormente, se efectuaron dos análisis de conglomerados jerárquicos con el objetivo de comprobar si las memorias y la superestructura se agrupaban. El segundo análisis de conglomerados jerárquico nos permitió realizar una clasificación de los niños y obtener distintos subgrupos de niños con TEL, en función del déficit en la memoria de trabajo y en la superestructura narrativa, el segundo de los objetivos planificados.
Por último, se realizaron análisis de varianza para establecer las relaciones existentes entre las distintas dimensiones lingüísticas que nos permitan identificar a los TEL y la memoria de trabajo.

\section{Resultados}

En la tabla 3 se muestran los estadísticos descriptivos de la pruebas en ambos grupos. Se realizó un contraste de hipótesis para cada una de ellas, resultando todas las pruebas significativas.

Discriminación de las pruebas de evaluación entre TEL y controles

El análisis discriminante permite descubrir qué instrumentos separan a los grupos. $\mathrm{Al}$ ser solo dos grupos resulta una única función $\left(\lambda=0.26 ; \chi^{2}=\right.$ $57.86 ; p=0.001)$. El resultado de la prueba de Box indicó que las matrices de covarianza poblacionales de los grupos eran iguales $(p=0.06)$. La matriz de estructura, que muestra las variables ordenadas por el tamaño de la correlación con la función obtenida, se presenta en la tabla 4.

Se observa como la prueba con mayor peso en la clasificación es la memoria verbal directa, siendo la aportación individual de todas las pruebas significativas, como puede verse en la tabla 4.

La función canónica discriminante obtenida permite clasificar correctamente al 95,8\% de los casos, siendo bien clasificados el $100 \%$ de los niños con TEL y $88.9 \%$ de los niños del grupo de control.

TABLA 3. Estadísticos descriptivos

\begin{tabular}{lccccccc}
\hline & \multicolumn{4}{c}{ Grupo } & \multicolumn{3}{c}{ Anova } \\
\cline { 2 - 5 } Prueba & \multicolumn{3}{c}{ TEL } & \multicolumn{2}{c}{ Control } & \multirow{2}{*}{ F } & \multirow{2}{*}{ P } \\
\cline { 2 - 5 } Media & D.T. & Media & D.T. & $(2,53)$ & & \\
\hline MT verbal & 3.17 & 0.91 & 4.56 & 0.78 & $21.29 * * *$ & 0.60 & 0.99 \\
MCP espacial & 2.27 & 0.87 & 3.11 & 0.96 & $4.78^{* *}$ & 0.25 & 0.87 \\
MT espacial & 3.73 & 0.94 & 4.50 & 0.79 & $9.75^{* * *}$ & 0.41 & 0.99 \\
Superestructura & 2.67 & 1.12 & 3.67 & 0.91 & $13.13^{* * *}$ & 0.48 & 0.99 \\
\hline
\end{tabular}

Nota: MT: Memoria de trabajo; MCP: Memoria corto plazo

$* \mathrm{p}<0.05 ; * \mathrm{*}<0.01 ; * * \mathrm{p}<0.001$

Fuente: elaboración propia 
Tabla 4. Matriz de estructura y pruebas de igualdad de las medias de los grupos

\begin{tabular}{llll}
\hline \multirow{2}{*}{ Pruebas } & \multirow{2}{*}{ Coeficiente estructura } & \multicolumn{2}{l}{ Pruebas de igualdad de las medias de los grupos } \\
\cline { 3 - 4 } & & Wilks & $\mathrm{F}$ \\
\hline MCP verbal & 0.855 & 0.615 & $28.84^{* * *}$ \\
MT verbal & 0.475 & 0.824 & $9.80^{* *}$ \\
MCP espacial & 0.283 & 0.846 & $8.36^{* *}$ \\
MT espacial & 0.277 & 0.818 & $10.21^{* *}$ \\
Superestructura & 0.256 & 0.330 & $93.54^{* * *}$ \\
\hline
\end{tabular}

Nota: MT: Memoria de trabajo; MCP: Memoria corto plazo $* \mathrm{p}<0.05 ; * \mathrm{p}<0.01 ; * * \mathrm{p}<0.001$

Fuente: elaboración propia

\section{Clasificación de los sujetos}

Mediante la aplicación de un análisis de conglomerados jerárquico a nuestros datos (figura 1), se puede observar que resultan dos conglomerados. En el primero se agrupa la superestructura con las memorias de trabajo. En el segundo se concentran las dos memorias a corto plazo.

A partir de estos conglomerados, se pueden separar a los participantes con TEL en perfiles diferenciados. Se puede observar en la figura 2 la separación en tres subgrupos de los niños con TEL (se omite de la figura la representación de la agrupación de los niños del grupo de control).

Si se atiende al cruce de los dos dendrogramas anteriores para obtener la representación visual de cada uno de los grupos, puede observarse que existe una importante diferencia cromática entre los niños del grupo TEL y los del control (el tono será más oscuro cuanto mayor gravedad exista en la dimensión), tal como aparece en la figura 3.

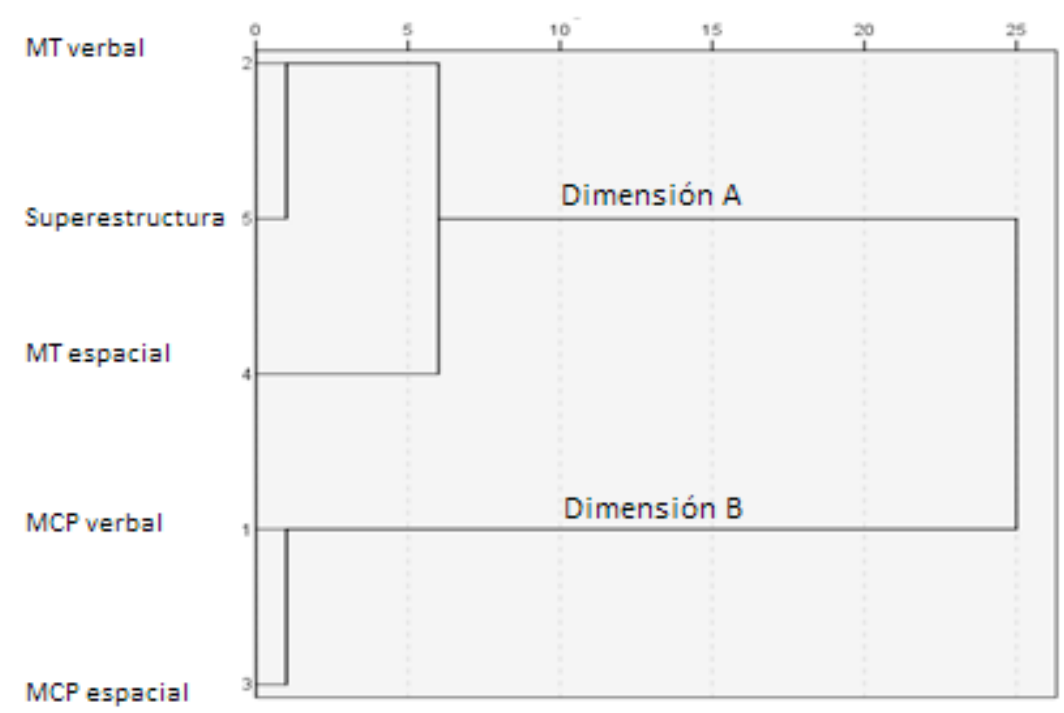

Figura 1. Dendrograma a partir de la vinculación media entre grupos

Fuente: elaboración propia 


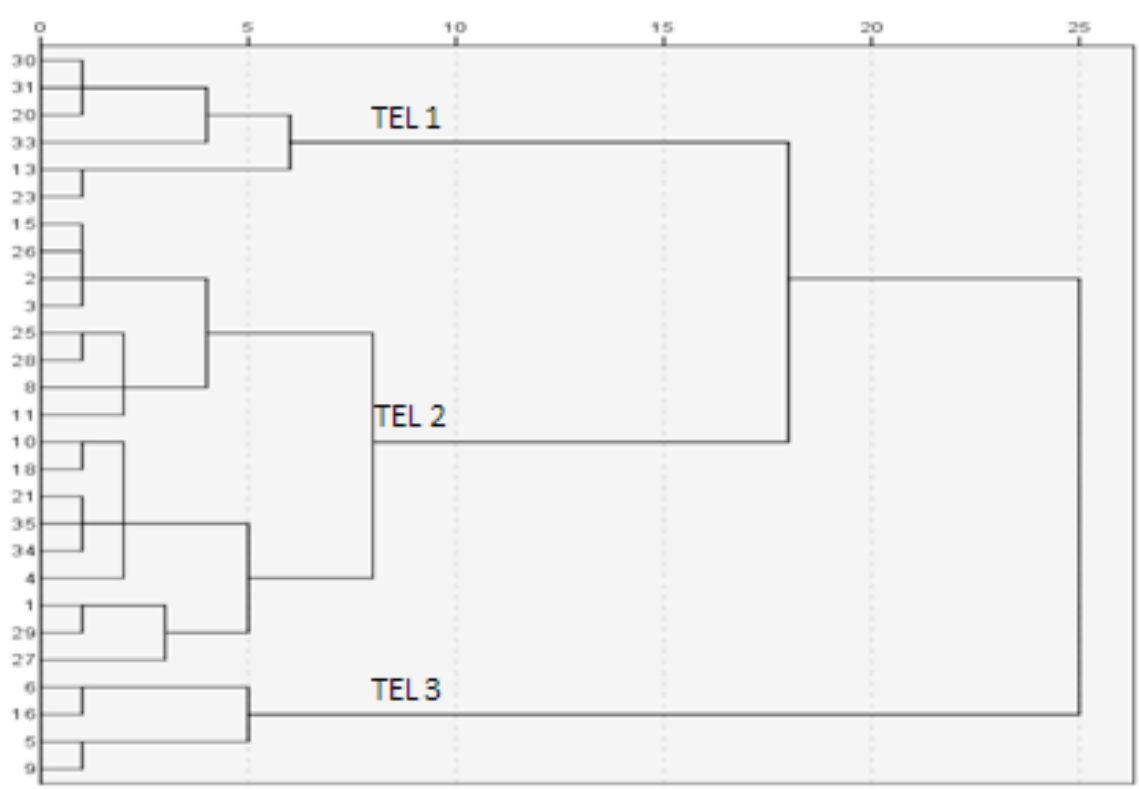

Figura 2. Dendrograma que representa los conglomerados de participantes

Fuente: elaboración propia

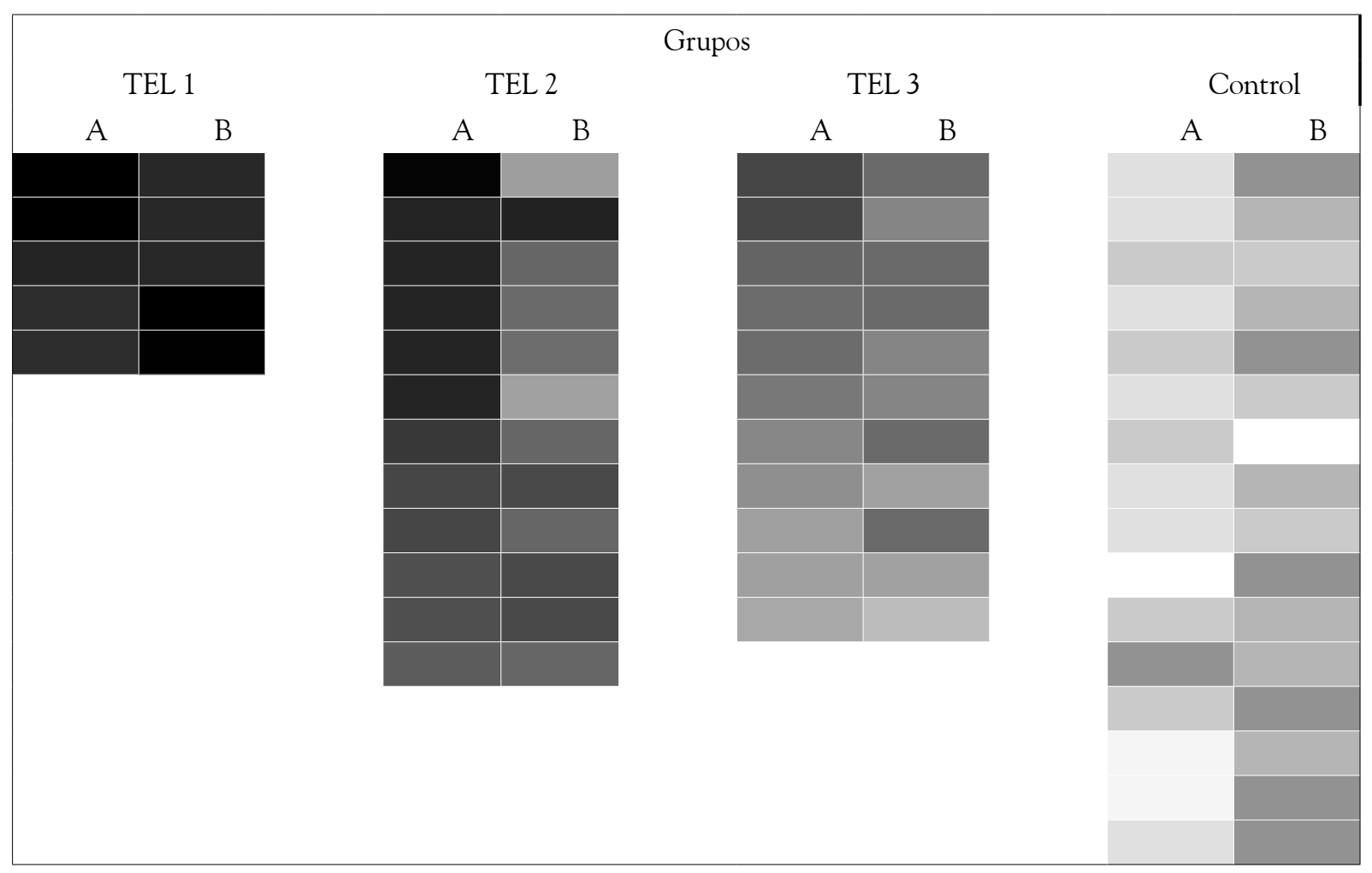

Figura 3. Cruce cromático de dendrogramas

Fuente: elaboración propia 
Conglomerados: A: MT espacial +

MT verbal + Superestructura y B:

MCP espacial + MCP verbal

En cuanto al grupo con TEL, se pueden establecer tres subtipos atendiendo al déficit en la memoria. Así, se presenta un primer grupo (TEL 1) con déficit severo en ambas dimensiones. Otro grupo (TEL 2) con un déficit severo en la primera dimensión (conformada por la MT verbal, la MT espacial y la superestructura) y moderado en la segunda dimensión (conformado por las MCP). El tercer grupo (TEL 3) con déficit moderado en ambas dimensiones.

\section{Diferencias entre los grupos}

en las dos dimensiones

Una vez determinados los subgrupos TEL en función del déficit en memoria, se realizó un análisis de varianza para comprobar entre qué grupos producía diferencias cada una de ellas. El efecto principal de cada dimensión resultó significativo: A $\left(F(3.40)=52.94 ; p=0.001 ; \eta p^{2}=0.80\right)$ у $\mathrm{B}$ $\left(F(3.40)=21.36 ; p=0.001 ; \eta p^{2}=0.62\right)$. En la tabla 5 se muestran los contrastes a posteriori, que nos permiten observar los grupos que distingue cada dimensión. Así la dimensión A, separa los dos primeros grupos TEL de los otros dos, lo que podríamos denominar déficit severo en esta dimensión. Además, separa al 3 del grupo control (4), denominándolo como déficit medio. Por su parte, la dimensión B, separa al primer grupo del resto (déficit severo) y a los grupos 2 y 3 (déficit medio) del grupo control (4).

Efecto diferencial de las pruebas de evaluación diagnóstica en los subgrupos TEL por déficit en memoria

A partir de la clasificación anterior, se llevó a cabo un análisis de varianza con las cinco pruebas que se utilizaron para el diagnóstico de los TEL (fonología por medio del RFI; narrativa: oraciones

TABLA 5. Contrastes a posteriori entre los grupos para cada una de las dimensiones TEL

\begin{tabular}{|c|c|c|c|c|}
\hline \multirow{2}{*}{ Dimensiones } & \multirow{2}{*}{ Grupos } & \multicolumn{3}{|c|}{ Grupos } \\
\hline & & TEL 1 & TEL 2 & TEL 3 \\
\hline \multirow{3}{*}{$\mathrm{A}(\mathrm{MT}+\mathrm{SE})$} & TEL 2 & -0.75 & & \\
\hline & TEL 3 & $-2.94 * * *$ & $-2.19 * * *$ & \\
\hline & Control & $-5.12 * * *$ & $-4.36 * * *$ & $-2.18 * * *$ \\
\hline \multirow{3}{*}{$\mathrm{B}(\mathrm{MCP})$} & TEL 2 & $-2.19 * *$ & & \\
\hline & TEL 3 & $-3.20 * * *$ & -1.01 & \\
\hline & Control & $-4.28 * * *$ & $-2.09 * * *$ & $-1.07 * * *$ \\
\hline
\end{tabular}

Nota: MT: Memoria de trabajo; SE: Superestructura; MCP: Memoria corto plazo

$* \mathrm{p}<0.05 ; * \mathrm{*}<0.01 ; * * \mathrm{p}<0.001$

Fuente: elaboración propia

TABba 6. Pruebas de efectos para cada dimensión

\begin{tabular}{lccc}
\hline Dimensiones & $\mathrm{F}(1,3)$ & $\eta \mathrm{p} 2$ & $\mathrm{P}$ \\
\hline A (Fonología-RFI) & $3.32^{*}$ & 0.21 & 0.71 \\
B (Narrativa-oraciones compuestas, mazes y errores gramaticales) & $12.63^{* * *}$ & 0.51 & 0.99 \\
C (Asociación auditiva y visual-ITPA) & $2.93^{*}$ & 0.19 & 0.65 \\
D (Expresión y comprensión lingüísticas-CELF-3) & $56.75^{* * *}$ & 0.82 & 0.99 \\
E (Vocabulario-Peabody) & 1.32 & 0.10 & 0.32 \\
\hline
\end{tabular}

Nota: $* \mathrm{p}<0.05 ; * * \mathrm{p}<0.01 ; * * \mathrm{p}<0.001$

Fuente: elaboración propia 
compuestas, mazes y errores gramaticales; asociación auditiva y visual del ITPA; lenguaje expresivo y comprensivo con el CELF-3 y vocabulario a través del Peabody). El efecto de cada una de las dimensiones estudiadas para la identificación y diagnóstico de los TEL resultó significativo, a excepción de la última (tabla 6).

Atendiendo a los efectos simples (tabla 7), se observa que las dimensiones $\mathrm{A}, \mathrm{C}$ y $\mathrm{E}$ no consiguen aprehender diferencias grupales en torno al déficit en la MT. Por su parte, la dimensión D, muestra diferencia entre el grupo control y el resto de los grupos. Por último, la dimensión B distingue estadísticamente entre los dos grupos con algún déficit severo en MT (TEL 1 y TEL 2) de los otros dos grupos, niños con déficits moderados y niños normales (TEL 3 y Control).

De los resultados anteriores parece desprenderse la presencia de problemas de memoria en los TEL, tanto en la MCP como en la MT, en sus dos modalidades verbal y espacial, pero estando más relacionados con algunas de las dimensiones lingüísticas que sirven para su diagnóstico, especialmente la narrativa y los procesos de expresión y comprensión lingüísticos.

\section{Discusión y conclusiones}

Cuando son comparados con sus iguales con desarrollo típico, los niños con TEL se muestran menos capaces de realizar con éxito un amplio número de tareas verbales y no verbales, por lo menos, de manera rápida y con el mismo nivel de eficacia (Leonard et al., 2007). Con todo, falta todavía mucho camino por recorrer en la búsqueda de un consenso acerca de cuáles son las causas subyacentes de tales limitaciones. Algunas explicaciones, dentro del amplio rango de las que se contemplan, incluyen los problemas en la habilidad para mantener y manipular la información en la memoria de trabajo (Gathercole \& Baddeley, 1990; Leonard et al., 2007), tanto en su forma verbal como espacial (Verche, Hernández, Quintero, \&, Acosta, 2013). Una deficiencia en esta destreza repercute claramente en el rendimiento lingüístico en general y en el narrativo, en particular (Duinmeijer, Jon, \& Scheper, 2012). De aquí que los niños con TEL presenten muchas dificultades en el procesamiento narrativo global y en la organización y aprendizaje de los diferentes elementos que integran la superestructura narrativa, de manera concreta.

TABLA 7. Contrastes a posteriori entre grupos para las pruebas de evaluación diagnóstica de los TEL

\begin{tabular}{|c|c|c|c|c|}
\hline \multirow{2}{*}{ Dimensiones } & \multirow{2}{*}{ Grupos } & \multicolumn{3}{|c|}{ Grupos } \\
\hline & & TEL 1 & TEL 2 & TEL 3 \\
\hline \multirow{3}{*}{ A(Fonología-RFI) } & TEL 2 & 0.19 & & \\
\hline & TEL 3 & 0.41 & 0.21 & \\
\hline & Control & -1.56 & -1.75 & -1.97 \\
\hline \multirow{3}{*}{ B (Narrativa-oraciones compuestas, mazes y errores gramaticales) } & TEL 2 & 0.55 & & \\
\hline & TEL 3 & $-3.18 * *$ & $-2.62 * *$ & \\
\hline & Control & $-3.45 * * *$ & $-2.90 * * *$ & -0.27 \\
\hline \multirow{3}{*}{ C (Asociación auditiva y visual-ITPA) } & TEL 2 & -1.30 & & \\
\hline & TEL 3 & -0.84 & 0.46 & \\
\hline & Control & -2.54 & -1.24 & -1.70 \\
\hline \multirow{3}{*}{ D (Expresión y comprensión lingüísticas-CELF-3) } & TEL 2 & 0.26 & & \\
\hline & TEL 3 & -0.06 & -0.32 & \\
\hline & Control & $-3.44 * * *$ & $-3.70 * * *$ & $-3.38^{* * *}$ \\
\hline \multirow{3}{*}{ E (Vocabulario-Peabody) } & TEL 2 & 0.47 & & \\
\hline & TEL 3 & -0.08 & -0.54 & \\
\hline & Control & -0.32 & -0.79 & -2.48 \\
\hline
\end{tabular}

Nota: MT: *p $<0.05 ; * * p<0.01 ; * * p<0.001$

Fuente: elaboración propia 
Justamente, esta habilidad resulta esencial para la producción y comprensión de historias ficticias, y supone la base sobre la que poder organizar los aspectos micro estructurales relacionados con la coherencia y la cohesión narrativas. En cualquier caso, se necesita ahondar en este campo para establecer conexiones entre la producción narrativa y aspectos particulares del procesamiento cognitivo, como el papel jugado por la memoria. Entretanto la noción de una capacidad limitada en la MCP y en la MT sigue siendo un poderoso instrumento de interpretación. En consecuencia y atendiendo a las consideraciones anteriores, parece oportuno abordar el estudio que se ha presentado, al establecerse como objetivo general indagar en las posibles relaciones entre algunos componentes del lenguaje y determinados tipos de memoria y las implicaciones que los resultados puedan tener en la caracterización del TEL.

El primer objetivo diseñado intentaba dar respuesta a cómo se agrupaban la superestructura narrativa y las memorias espacial y verbal, en su doble forma de memoria de corto plazo y memoria de trabajo. El análisis de conglomerados estableció dos dimensiones agrupando, por un lado, a las dos memorias de trabajo: verbal y espacial, con la superestructura narrativa, y por otro, a las dos memorias de corto plazo. Este primer resultado parece poner en relación la capacidad de organizar y estructurar historias con un tipo de memoria que requiere no solo mantener la información, sino también controlarla y manipularla (Baddeley, 2012). Esta idea conecta con el siguiente objetivo que nos ayuda a diferenciar distintos subtipos de TEL.

En efecto el segundo objetivo perseguía encontrar distintos subtipos de TEL teniendo en cuenta el déficit en las dos modalidades de memoria y en la superestructura narrativa. En los resultados aparece de nuevo la noción de heterogeneidad en los TEL (Leonard, 2014) al no haber un patrón de comportamiento similar, sino que por el contrario, estamos ante la presencia de diferentes subgrupos con características diferenciadas, con las implicaciones que ello puede tener de cara a la intervención psicopedagógica y fonoaudiológica. Parece interesante destacar la existencia de un comportamiento distinto en función del tipo de memoria que se contemple. De tal forma que en los dos primeros subtipos hay siempre una severidad en la MT, verbal y espacial y un comportamiento muy deficitario en la superestructura narrativa. Ello nos lleva a plantearnos un mayor peso explicativo en este tipo de déficits narrativos, sustentado en una mayor gravedad de la MT y no tanto de la MCP. Nuestros datos están respaldados en algunas investigaciones previas en las que ya se habla de la relación entre la MT y la competencia narrativa. Al parecer los aspectos centrales o estructurales de una historia necesitan estar disponibles y operativos en la mente, al objeto de poder disponer en cada momento de los elementos claves de la superestructura narrativa (Boudreau $\&$ Costanza, 2011). De igual forma, en un trabajo reciente Dodwell y Bavin (2008) encontraron una correlación significativa entre la MT y una tarea de recontado de una historia, en la que posteriormente se medía la superestructura en niños con TEL de seis años de edad. Múltiples estudios realzan la importancia de la MT para alcanzar una competencia narrativa, argumentando que la ordenación estructural de una historia requiere de una organización adecuada de la información con respecto al contenido, pero también demanda una disposición acertada que garantice una conexión entre las distintas partes del discurso, jugando la MT un papel fundamental (Boudreau \& Costanza, 2011; Montgomery, Polunenko, \& Marinellie, 2009).

En relación al tercer objetivo del presente estudio, en el que se pretendía estudiar los vínculos entre los déficits de memoria y los distintos componentes lingüísticos considerados para el diagnóstico del TEL, se alcanzaron resultados interesantes. Se produce por un lado, una relación entre los datos obtenidos en la expresión y comprensión lingüísticas y los problemas de memoria que permiten diferenciar entre los niños del grupo control y los tres subtipos de TEL atendiendo al déficit en la memoria y por otro lado, si se quiere separar los grupos con déficits severos en memoria de los que presentan un déficit moderado o un desarrollo típico, hay que atender a la dimensión relacionada con la narrativa.

Finalmente, el estudio de las habilidades narrativas ha demostrado su validez en la identificación 
y caracterización de los TEL e incluso en la predicción del rendimiento académico futuro. Ahora bien, su consideración junto con otras habilidades lingüísticas y especialmente con otras de naturaleza más cognitiva como la memoria ha sido menos investigada. Examinar esta relación tal y como se ha hecho en el presente estudio, está plenamente justificada en niños con TEL, pues estos se caracterizan por una diversidad de problemas lingüísticos, que muy a menudo se ven acompañados de limitaciones, tal y como nos recuerdan Gillam, Montgomery y Gillam (2009), en otros dominios cognitivos como la memoria.

\section{Referencias}

Acosta, V. Moreno, A., \& Axpe, A. (2012). Implicaciones clínicas del diagnóstico diferencial temprano entre Retraso de Lenguaje (RL) y Trastorno Específico del Lenguaje (TEL). Universitas Psychologica, 11(1), 279-291.

Acosta, V., Ramírez, G., \& Hernández, S. (2013). Identificación y clasificación de alumnado con Trastorno Específico del Lenguaje. Revista de Logopedia, Foniatría y Audiología, 33, 157-164.

Aguilar, E., Sanz-Torrent, M., \& Serra, M. (2002). A comparative study of the phonology of pre-school children with specific language impairment, language delay and normal acquisition. Clinical Linguistic $\mathcal{E}$ Phonetics, 16(8), 573-596.

Archibald L., \& Gathercole, S. (2006). Short-term and working memory in specific language impairment. International Journal of Language and Communication Disorders, 41, 675-693.

Baddeley, A. (2012). Working memory: Theories, models, and controversies. Annual Review of Psychology, 63, 1-29.

Bavin, E., Wilson, P., Maruff, P., \& Sleeman, F. (2005). Spatio visual memory of children with specific language impairment: evidence for generalized processing problems. International Journal of Language E Communication Disorders, 40(3), 319-332

Bedore, L., \& Leonard, L. (2001). Grammatical morphology deficits in Spanish-speaking children with specific language impairment. Journal of Speech, Language, and Hearing Research, 44, 905-924.
Boudreau, D., \& Costanza, A. (2011). Assessment and treatment of working memory deficits in schoolage children: The role of the speech-language pathologist. Language, Speech, and Hearing Services in Schools, 42, 152-166.

Cain, K., Oakhill, J., \& Bryant, P. (2004). Children's reading comprehension ability: Concurrent prediction by working memory, verbal ability, and component skills. Journal of Educational Psychology, 96, 31-42.

Conti-Ramsden, G., Botting, N., \& Faragher, B. (2001). Psycholinguistic markers for specific language impairment (SLI). The Journal of Child Psychology and Psychiatry and Allied Disciplines, 42, 741-748.

Dodwell, K., \& Bavin, E. (2008). Children with specific language impairment: an investigation of their narratives and memory. International Journal of Language EF Communication Disorders, 43, 201-218.

Duinmeijer, I., Jon, J., \& Scheper, A. (2012). Narrative abilities, memory and attention in children with a specific language impairment. International Journal of Language $\mathcal{E}$ Communication Disorders, 47(5), 542-555.

Dunn, L., Padilla, E., Lugo, D., \& Dunn, L. (1986). Test de vocabulario en imágenes Peabody. Madrid: TEA.

Ellis Weismer, S., Tomblin, J., Zhang, X., Buckwalter, P., Chynoweth, J., \& Jones, M. (2000). Nonword repetition performance in school-age children with and without language impairment. Journal of Speech, Language, and Hearing Research, 43, 865-878.

Gabriel, A., Stefaniak, N., Maillart, C., Schmitz, X., \& Meulemans, T. (2012). Procedural Visual Learning in Children with Specific Language Impairment. American Journal of Speech-Language Pathology, 21, 329-341.

Gathercole, S., \& Baddeley, A. (1990). Phonological memory deficits in language disordered children: Is there a causal connection? Journal of Memory and Language 29, 336-360.

Gillam, R., Cowan, N., \& Marler, J. (1998). Information processing by school-age children with specific language impairment: Evidence from a modality effect paradigm. Journal of Speech, Language, and Hearing Research, 41, 913-926. 
Gillam, R., Montgomery, \& Gillam, S. (2009). Memory and attention in children with language impairments. En R. Schwartz (Ed.), Handbook of Child Language Disorders (pp. 201-225). New York, NY: Psychology Press.

Hincapié, L., Giraldo, M., Lopera, F., Pineda, D., Castro, R., Lopera, J.. ... Lopera, E. (2008). Trastorno Específico del Desarrollo del Lenguaje en una población infantil colombiana. Universitas Psychologica, 7(2), 557-569.

Im-Bolter, N., Johnson, J., \& Pascual-Leone, J. (2006). Processing limitations in children with specific language impairment: The role of executive function. Child Development, 77, 1822-1841.

Kaufman, A., \& Kaufman, N. (2000). Test Breve de Inteligencia de Kaufman (K-BIT). Madrid:

TEA Ediciones.

Kirk, S., McCarthy, J., \& Kirk, W. (2005). Test Illinois de Habilidades Psicolingüísticas. Madrid: TEA Ediciones.

Leonard, L. (2014). Children with specific language impairment. $2^{\mathrm{o}}$ edición revisada. Cambridge: MIT Press.

Leonard, L., Ellis, S., Miller, C., Francis, D., Tomblin J., \& Kail, R. (2007). Speed of processing, working memory, and language impairment in children. Journal of Speech, Language, and Hearing Research, 50, 408-428.

Marton, K., Campanelli, L., Eichorn, N., Scheuer, J., \& Yoon, J. (2014). Information Processing and Proactive Interference in Children With and Without Specific Language Impairment. Journal of Speech, Language, and Hearing Research, 57, 106-119

Mayer, M. (1969). Frog, where are you? Nueva York: Penguin Books.

Montgomery, J., Polunenko, A., \& Marinellie, S. (2009). Role of working memory in children's understand- ing of spoken narrative: A preliminary investigation. Applied Psycholinguistics, 30, 485-509.

Pavez, M., Coloma, C., \& Maggiolo, M. (2008). El desarrollo narrativo en niños. Barcelona: Ars Médica.

Quintero, I., Hernández, S., Verche, E., Acosta, V., \& Hernández, A. (2013). Disfunción ejecutiva en el trastorno específico del lenguaje. Revista de Logopedia, Foniatría y Audiología, 33, 172-178.

Sanz-Torrent, M. (2002). Los verbos en niños con Trastorno Específico del Lenguaje. Revista de Logopedia, Foniatría y Audiología, 22(2), 100-110.

Sanz-Torrent, M., Serrat, M., Andreu, Ll., \& Serra, M. (2008). Verb morphology in Catalan and Spanish in children with Specific Language Impairment: a developmental study. Clinical Linguistic $\mathcal{E}$ Phonetics, 22(6), 459-474.

Semel, E., Wiig, E., \& Secord, W. (2003). Clinical Evaluation of Language Fundamentals - Fourth Edition. San Antonio, TX: Psychological Corporation.

Strömqvist, S., \& Verhoeven, L. (2004). Relating Events in Narrative. Vol. 2. Nueva York: Psychology Press.

Ullman, M., \& Pierpont, E. (2005). Specific language impairment is not specific to language: the procedural deficit hypothesis. Cortex, 41, 399-433

Verche, E., Hernandez, S., Quintero, I., \& Acosta, V. (2013). Alteraciones de la memoria en el trastorno específico del lenguaje: una perspectiva neuropsicológica. Revista de Logopedia, Foniatría y Audiología, 33, 179-185.

Wechsler, D. (1997). Wechsler Memory Scale-Third Edition. San Antonio, TX: The Psychological C.

Wechsler, D. (2005). Escala de Inteligencia de Wechsler para niños. WISC-IV. Cuarta Edición. Madrid: TEA Ediciones. 
